See discussions, stats, and author profiles for this publication at: https://www.researchgate.net/publication/330292546

\title{
Financial Difficulties in Bipolar Disorder Part 2: Psychological Correlates and a Proposed Psychological Model.
}

Article in Journal of Mental Health · January 2019

CITATIONS

0

3 authors:

Thomas Richardson

Solent NHS Trust

110 PUBLICATIONS 1,674 CITATIONS

SEE PROFILE

Chris Fitch

University of Bristol

9 PUBLICATIONS 26 CITATIONS

SEE PROFILE
READS

52

Megan Jansen

AOL

8 PUBLICATIONS 55 CITATIONS

SEE PROFILE

Some of the authors of this publication are also working on these related projects:

An evaluation of predictors of dropout from an Emotional Coping Skills programme in a community mental health service View project

Project Test of a Cognitive Model of Cannabis related Paranoia View project 


\section{This is an Author's Original Manuscript published in the Journal of Mental Health.}

\section{Epub ahead of print doi/0000- 0002-5357-4281}

\section{http://tinyurl.com/y6xrgru7}




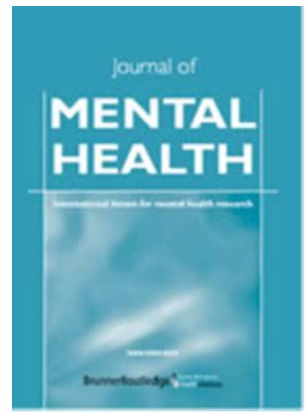

Financial Difficulties in Bipolar Disorder Part 2: Psychological Correlates and a Proposed Psychological Model.

\begin{tabular}{|r|l|}
\hline Journal: & Journal of Mental Health \\
\hline Manuscript ID & CJMH-2018-0263 \\
\hline Manuscript Type: & Original Article \\
\hline Subject Area: & Mood Disorders \\
\hline Further Detail: & Bipolar Disorder, Finances, Debt, Compulsive Buying \\
\hline \multicolumn{2}{|l}{} \\
\hline
\end{tabular}

\section{SCHOLARONE}

Manuscripts 


\title{
Financial Difficulties in Bipolar Disorder Part 2: Psychological Correlates and a Proposed Psychological Model.
}

\begin{abstract}
Objectives: A number of psychological variables have been shown to be prominent in Bipolar Disorder. However no research has looked at the relationship between financial difficulties and psychological factors in Bipolar Disorder.

Aims: This study aims to look at the relationship between financial difficulties and psychological factors in Bipolar Disorder.

Method: 54 participants with diagnosis of Bipolar Disorder in an adult secondary care NHS mental health service completed the questionnaire pack which included measures examining financial variables including difficulty paying bills, and perceived financial wellbeing. Questionnaires measured self-esteem, impulsivity, mindfulness and dysfunctional attitudes.

Results: Financial difficulties cross-sectionally were related to a number of psychological variables such as mindfulness and impulsivity. Over time the strongest effects were for compulsive spending which was increased over time by higher dependency and achievement cognitions, lower mindfulness and lower self-esteem. Poor perceived financial wellness lower self-esteem over time. A psychological model incorporating these and related findings is presented.
\end{abstract}

Conclusion: Psychological factors appear to be related to financial difficulties in Bipolar Disorder. Future research is needed to confirm the model presented here and develop interventions.

Declaration of Interest: MJ has no conflicts of interests. CF undertakes a programme of research, training, and intervention with financial services organisations on mental health, but this has no direct bearing on the findings reported in this paper. TR has presented some of the results of this study to a finance company, for which money has been donated to a charity. He 


\begin{abstract}
also presented unpaid to charity and wrote a blog about this research. TR has been paid as a consultant and will receive royalties from a software company for developing an intervention around financial difficulties and mental health which uses insights from his own research including this paper, as well as findings from other published research in the area. This study was funded via Research Capability Funding from National Institute for Health Research via Solent NHS Trust.
\end{abstract}

Keywords: Bipolar Disorder; Finances; Debt; Compulsive Buying. 


\title{
Financial Difficulties in Bipolar Disorder Part 2: Psychological Correlates and a Proposed Psychological Model.
}

\begin{abstract}
Introduction
Bipolar Disorder is characterised by episodes in hypomania or mania and episodes of depression. These extremes are estimated to affect $2-3 \%$ of the general population (Merikangas, 2011). The diagnostic criteria for a hypo(manic) episode includes symptoms of inflated self-esteem, increased talkativeness, goal directed behaviour, participating in risky behaviours, racing thoughts, distractibility and a decreased need for sleep (APA, 2013). In contrast, a depressive episode typically includes symptoms of depressed mood or irritability, fatigue, decreased interest or pleasure in usual activities, guilt/worthlessness, diminished ability to concentrate and suicidality (APA, 2013). Both of these mood extremes can result in significant functional impairment and can lead to psychological, social and economic problems (Cheema et al., 2015).A number of studies have demonstrated the psychological profile of those with a diagnosis of Bipolar Disorder. This paper will now review some key psychological variables and consider how they might be related to financial difficulties.
\end{abstract}

\section{Impulsivity}

Impulsivity has been shown to be high in those with a diagnosis of Bipolar Disorder (Muhtadie et al., 2014), and to impact manic symptom severity and course (Najt et al., 2007; Strakowski et al., 2009; Swann et al., 2001). During a hypo(manic) episode, individuals have been shown to have an increased likelihood of partaking in disruptive behaviours such as impulse spending, gambling, sexual indiscretions, and initiating grand schemes (Muhtadie et al., 2014). Fletcher et al. (2013) found that $70 \%$ of patients reported impulse spending when hypomanic, and those with Bipolar Disorder have more symptoms of compulsive buying (Kesebir, İşitmez, \& Gündoğar, 2012). 
Cheema et al. (2015) found that Bipolar Disorder patients have a diminished ability to effectively and this appeared to be related to impulsivity. Finally, research shows that compulsive buyers have higher levels of impulsivity (Williams \& Grisham, 2012). Thus impulsivity might be related to impulse spending and other financial difficulties in Bipolar Disorder; however no studies have examined these relationships over time..

\section{Self-Esteem}

A meta-analysis conducted by Nilsson et al. (2010) found that Bipolar Disorder patients in comparison to controls exhibited lower self-esteem between episodes. Studies have also shown that self-esteem predicts changes in depression over time in Bipolar Disorder (Johnson, Meyer, Winett, \& Small, 2000). There are two potential links between self-esteem and financial difficulties. Firstly, Wickrama, Surjadi, Lorenz, Conger, \& O’Neal, (2012) found that self-esteem mediated the relationship between financial hardships and mental health, though other studies have found no such mediating relationships (Burdette, Hill, \& Hale, 2011). Secondly, self-esteem may be related to impulsive spending as it has also been found to predict risk taking behaviours in adolescents (Auerbach \& Gardiner, 2012).However no research has examined the link between self-esteem and financial variables in Bipolar disorder specifically.

\section{Dysfunctional Assumptions}

Those with Bipolar Disorder have shown higher scores on dysfunctional attitudes than healthy controls (Scott et al., 2000) with higher scores for goal attainment and antidependency being evident (Lam et al., 2004). Lam et al. (2004) hypothesise that goal attainment cognitions might be related to over spending. These might be relevant if impulse 
spending is goal focused: mania is characterised by an increased in goal-directed behaviour (APA, 2016). Thus dysfunctional assumptions may be related to impulsive behaviours such as compulsive spending in Bipolar disorder; however no research has examined this at present.

\section{Mindfulness}

Finally, mindfulness may be related to finances in Bipolar disorder. Preliminary research has shown potential for mindfulness in Bipolar Disorder for improving quality of life (Murray et al., 2015),depression symptoms (Weber et al., 2010; Williams et al., 2008) and anxiety (Perich, Manicavasagar, Mitchell, Ball, \& Hadzi-Pavlovic, 2013). However impact on relapse rates has not yet been examined. The relationship between finances and mindfulness in the context of Bipolar disorder has not yet been examined, though research with has shown lower levels of mindfulness in those with compulsive spending (.Williams \& Grisham, 2012).

To summarise, research has shown that psychological factors such as self-esteem differ in those with Bipolar Disorder, and research with other populations shows a potential role with financial difficulties. Paper 1 (Richardson, Jansen, \& Fitch, Submitted) which used the same sample as this current paper, showed relationships between mental health and a number of financial variables over time. This study aimed to build on this by examining whether psychological variables are related to financial difficulties in Bipolar Disorder, in order to develop a psychological model to guide future research and assist clinical practice.

\section{Method}

\section{Design}


The present study used a longitudinal design. Ethical approach was granted by the University Of Southampton School Of Psychology Ethics Committee as well as the local NHS research ethics committee

NRES Committee South Central- Hampshire B, 15/SC/0436.)

\section{Recruitment}

This study is using data from a linked study on mental health and finances in Bipolar Disorder (Richardson et al., Submitted) with a linked qualitative study (Richardson et al., 2017). Those with Bipolar Affective Disorder (type I, type II or unspecified) participants were invited to take part by their secondary care community adult mental health clinician in Portsmouth. Those with a diagnosis of cyclothymia were excluded. Participants could be in remission/stable, depressed or hypomanic, however they had to have capacity to give informed consent to take part in the study. Participants had to be 18 years or older.

An invitation pack that included a poster advertising the study, the participant information sheet and an opt-in form were either handed to clients or posted to those deemed suitable by their clinician. In order to opt-in to the study, participants were required to either return the reply slip of the opt-in form or phone or email the research team to express their interest.

\section{Participants}

Fifty-eight participants opted into the study from 149 who were invited. 54 then took part at time 1 and 40 at time 2. See Richardson et al (submitted) for full details on participants' characteristics. Clients were $68.5 \%(n=37)$ female and $77.8 \%(n=42)$ White British with a mean age of 48 years. $61.1 \%(n=33)$ were unemployed, $33.3 \%(n=38)$ had a comorbid diagnosis and $55.6 \%(n=50)$ were reported as in a euthymic state. 


\title{
Procedures
}

The researcher met with participants within the outpatient NHS hospital setting or the participant's home. Written consent was obtained. Participants completed a series of questionnaires at two time points approximately four months apart.

\begin{abstract}
Measures
The following measures were given at both time points. The chronbachs alpha for the current sample at time one are given.
\end{abstract}

\section{Finances}

- Compulsive buying measurement scale (Valence, d'Astous, \& Fortier, 1988): This a measure of compulsive buying with 13 questions such as "When I have money I cannot help but spent part or all of it" and "There are times when I have a strong urge to buy." The original research showed good reliability in compulsive and noncompulsive shoppers $\alpha=.88$. Higher scores represent more symptoms of compulsive buying. The psychometric properties in Bipolar disorder have not yet been tested however the internal consistency was excellent in the current sample $\alpha=.95$.

- Index of Financial Stress (Siahpush \& Carlin, 2006): A measure of 8 recent financial difficulties such as 'I was unable to heat home' and 'Asked for financial help from friends and family'. Higher scores represent greater financial difficulties. This has previously been used in longitudinal research on financial difficulties impacting eating disorder symptoms, psychotic symptoms and symptoms of depression and anxiety in a student sample (Richardson, Elliott, Roberts, \& Jansen, 2017; Richardson, Elliott, \& Waller, 2015; Richardson, Yeebo, Jansen, Elliott, \& Roberts, 
2018). The authors are not aware of this previously being used with Bipolar disorder, however the internal consistency was adequate in the current sample $\alpha=.74$.

- InCharge Financial Distress/ Financial Wellbeing Scale (Prawitz, Garman, Kim, \& Drentea, 2006; Prawitz, Garman, Sorhaindo, et al., 2006): A measure of perceived financial wellbeing with 8 questions such as 'How often do you worry about being able to meet normal monthly living expenses?' and How satisfied are you with your present financial situation?'. Higher scores represent greater satisfaction with current financial situation. This was chosen in particular as research has shown that subjective worry about debt is more important than amount of debt (Drentea \& Reynolds, 2012). Previous studies have shown that scores on this predict greater overall distress in cancer patients (Meeker et al., 2016). There have been no previous studies to the authors knowledge using this measure with Bipolar Disorder but the internal consistency in the current sample was excellent $\alpha=.95$.

\section{Psychological Correlates}

- Rosenberg Self-Esteem Scale (Rosenberg, 1989): A 10 item self-report measure of global self-esteem with via questions such as "On the whole I am satisfied with myself" and "I certainly feel useless at times". Higher scores suggest higher selfesteem. This measure has been used in previous research with Bipolar Disorder (Johnson et al., 2000), and the internal consistency in the current sample was excellent $\alpha=.90$.

- Mindful Attention Awareness Scale (Brown \& Ryan, 2003): 15 item measure mindfulness skills and attention to an individual's emotions and behaviour, via questions such as "It seems I am "running on automatic" without much awareness of what I'm doing" and "I find myself preoccupied with the future or the past." Higher 
scores show more mindfulness/greater awareness. This has previously been used in a trial of mindfulness based cognitive therapy for Bipolar Disorder (Perich et al., 2013), and the reliability was excellent in the current sample: $\alpha=.92$.

- Dysfunctional Attitude Scale 24 item version (Power et al., 1994): a measure of dysfunctional beliefs via questions such as. The subscales identified by (Lam et al., 2004) for Bipolar Disorder specifically were used here: Goal Attainment (e.g. "If I try hard enough, I should be able to excel at anything I attempt", internal consistency adequate in the current sample: $\alpha=.79$ ), Dependency (e.g. "What other people think about me is very important", internal consistency adequate in the current sample: $\alpha=.75$ ) and Achievement (e.g. "If I am to be a worthwhile person, I must be truly outstanding in at least one major respect", internal consistency adequate in the current sample: $\alpha=.77)$. Higher scores represent greater dysfunctional attitudes.

- Barratt Impulsivity Scale: 15 item version (Spinella, 2007): This is a brief version of a widely used measure of impulsivity using questions such as 'I act on the spur of the moment' and "I plan for the future". Greater scores demonstrate greater impulsivity. The full 30-item measure has been used in many studies with Bipolar Disorder (e.g. (Swann et al., 2005). This scale has a similar factor structure and internal consistency to the longer 30-item version (Spinella, 2007). The current sample has adequate internal consistency: $\alpha=.77$, similar to the $\alpha=.79$ achieved in the original validation paper with a community sample (Spinella, 2007)

\section{Statistical Analysis}

Correlations were used initially to examine cross-sectional correlations. There was insufficient sample size for multiple regression therefore partial correlations were used to look at longitudinal correlations. Missing data was filled in with the mode and the total scores 
then calculated as normal. There were low levels of missing data: a maximum of two people missing an item for the Compulsive Buying Scale, 1 for the Index of Financial Stress, InCharge scale, Self-Esteem Scale and Dysfunctional Attitudes Scale. One item on the Mindfulness scale had 6 people not completing but 1 for the remaining items. Similarly for Impulsivity there was one item with 3 participants missing but the remaining questions had one participant missing.

Non-normal distribution was identified via visual inspection of histograms and looking at whether kurtosis and skewness were outside of $-/+2$ ranges. Variables which were non-normally distributed could not be examined via partial correlation.

\section{Results}

\section{Correlations}

All variables were normally distributed except for the Index of Financial Stress (IFS). Table 1 displays the correlations between financial and psychological variables at time 1 . All correlations and partial correlations are one-tailed.

\section{** Insert Table 1 here**}

Variables which were significant at baseline were correlated with those scores at time 2. If this was significant than a partial correlation was performed to see whether the impact held over time after controlling for baseline scores (this could not be done for the IFS which was non-normally distributed).

Table 2 demonstrates the correlations for the psychological variables at baseline with financial variables at time two, before and after controlling for baseline financial variable scores. These showed that greater compulsive spending at time two was significantly predicted by lower self-esteem, lower mindfulness and higher dependency and achievement 
dysfunctional assumptions at baseline after controlling for baseline compulsive spending. There were no significant correlations over time for baseline psychological variables on time two perceived financial distress/wellness, once baseline financial distress/wellbeing was controlled for.

\section{** Insert Table 2 here**}

Table 1 also demonstrates the correlations for the financial variables at baseline with psychological variables at time 2 , before and after controlling for baseline psychological variables. The only significant variable which held over time were that greater financial distress/wellbeing at baseline correlated with greater self-esteem at time two after controlling for baseline self-esteem. Discussion

This study used a longitudinal design to examine the relationship between financial and psychological variables over time in Bipolar Disorder. Previous research has examined symptoms of compulsive buying in Bipolar Disorder but not psychological mechanisms (Kesebir et al., 2012). Other studies have only examined the role of a single variable (Cheema et al., 2015).

A number of variables were significant at one time point with financial difficulties being correlated with greater impulsivity and reduced mindful awareness. It could be that impulsivity leads to financial difficulties due to poor financial management, however due to the non-normal distribution it is not possible to examine longitudinal relationships for this variable. Goal attainment cognitions were also correlated with compulsive spending, however this did not hold over time. This is perhaps surprising given impulse spending is given as a potential goal-focused behaviour which causes difficulties in the diagnostic criteria for a manic episode (APA, 2013). It is also unexpected that the effect of impulsivity on compulsive 
spending did not hold over time given that this has previously been related to poor financial management in Bipolar Disorder (Cheema et al., 2015), and compulsive spending outside of Bipolar Disorder (Williams \& Grisham, 2012).It is possible that for some variables longitudinal results may not be statistically significant due to a reduced sample size and resulting lower statistical power at time 2 .

A number of psychological variables remained significantly related to financial variables over time with the strongest effects for compulsive spending. Dysfunctional assumptions around dependency and achievement increase compulsive spending over time. For dependency and compulsive spending the relationship appeared to work both ways: compulsive spending predicted greater later dependency and vice versa It has previously only been hypothesised that dysfunctional assumptions might fuel impulse spending (Lam et al., 2004): this study represents the first time such a potential link has been suggested empirically.

Compulsive spending also appeared to be increased over time by lower self-esteem Previous studies have shown that self-esteem is an important psychological variable in the relationship between financial difficulties and depression (Wickrama et al., 2012), however this is the first time that a relationship has been shown for Bipolar disorder. The current findings are in line with studies showing that compulsive buying is associated with low selfesteem (Müller, Mitchell \& de Zwaan , 2015). Poorer perceived financial wellness also appeared to lowered self-esteem over time. Study 1 (Richardson et al., submitted) found that poorer perceived financial wellness increased anxiety and stress over time. It is possible that self-esteem is a mediating factor between this relationship however this cannot be examined in the current sample. 
For all variables relationships were examined over time in order to try and determine whether psychological variables predicted later financial variables or vice versa. Broadly speaking the results appear to suggest that psychological variables appear to predict later financial variables over time rather than the other way around. However this study only had a four month follow-up period and a longer study may have shown different patterns over time.

Finally, poorer mindfulness awareness appeared to increase compulsive spending symptoms over time. Previous research has shown a relationship between mindfulness and compulsive spending (Williams \& Grisham, 2012), this is the first time to the author knowledge that such a relationship has been shown in Bipolar disorder specifically.

\section{Proposed Psychological Model}

The above findings from this study were combined with previous findings from this sample which are summarised in table 3. It is important to note the limitations of the quantitative data given a small sample size and short-follow up period. It is also important to note that for some themes in the qualitative study, relatively small numbers of participants responded in ways which fitted into the themes. It is therefore important to say that this model is not attempting to apply to everybody with Bipolar disorder and financial difficulties, but rather is trying to demonstrate a number of potential relationships, which will likely not apply to all individuals. It is also important to note that the terms impulsive spending/compulsive spending are used interchangeably as the qualitative study identified impulsive spending as a theme: some individuals may meet criteria for impulse spending here but the term here is not necessarily meant in the clinical sense of the word but rather to denote emotion-drive impulsive spending.

Figure 1 shows the proposed psychological model of the relationship between mental health and financial difficulties in Bipolar Disorder which takes into account all of these findings. 


\section{**Insert figure 1 and table 3 here**}

Financial stress (being unable to pay the bills) leads to poorer perceived financial wellness and needing to go without items such as new clothes or socialising. These then lead to negative affect via self-esteem. This negative affect than leads to compulsive spending via comfort spending: Previous research has suggested a role for negative affect in impulsive spending (Silvera, Lavack, \& Kropp, 2008) The negative affect can also lead to poor mindfulness (improvements in mindfulness have been linked with improvements in depression in Bipolar Disorder, Weber et al., 2010), which then makes individuals more susceptible to impulse spending: Impulsive spending then worsens financial difficulties. Unstable employment (identified as a theme and demonstrated by $61 \%$ unemployment in the sample) due to mental health problems can exacerbate financial difficulties and also lower self-esteem due to relying on benefits.

Financial difficulties lead to poor perceived financial wellness which leads to anxiety and stress. This anxiety and stress leads to avoidance of finances and poor financial planning which further exacerbates financial difficulties.

Impulsive spending might lead to regret and guilt about such purchases, which then increases dependency cognitions on others, for example feeling like you need the approval of others. Previous research has shown that guilt is commonly reported consequence of high risk behaviours when manic such as impulse spending (Fletcher et al., 2013). A coping mechanism for this might be increased generosity to others, which then fuels further impulse spending.

Finally there is a hypomanic cycle whereby financial difficulties lead to cognitions in particular around a need for achievement perhaps to solve financial difficulties: Previous 
research has shown that those with Bipolar Disorder have greater ambitions for personal wealth and that these increase manic symptoms over time (Johnson \& Carver, 2006; Johnson \& Carver, 2012). This leads to a plan to make money for example a risky business venture which increases hypomanic symptoms and leads to compulsive spending. Essentially this cycle is that those with Bipolar Disorder are struggling financially and they then 'spend money to make money' to try and get themselves out of this situation but it might actually make things worse. This links here to the concept of 'Ascent Behaviours' in the integrative cognitive model of mood swings (Mansell et al., 2007), whereby dysfunctional assumptions impact appraisals of early warning signs and coping strategies. For example somebody with a belief about the important to work hard may notice they are becoming manic and try to 'use' this energy to set up a business which might end up losing them money. It is important to note that study 1 did not find a relationship between current manic symptoms and compulsive spending, however it might have been that the follow-up was no longer enough to detect a relationship for current manic symptoms As study 1 found a correlation with past hypomanic symptoms this has been tentatively included in the model.

\section{Clinical Implications}

The findings from this study and the linked model suggest that a number of psychological mechanisms might be beneficial. For example mindfulness has been shown to be beneficial in Bipolar Disorder quantitatively (Miklowitz et al., 2009; Weber et al., 2010; Williams et al., 2008) and qualitatively (Chadwick et al., 2011). The current findings suggest that increased mindfulness might reduce compulsive spending in Bipolar Disorder. Strategies from Dialectical Behaviour Therapy which has been adapted for Bipolar Disorder (Van Dijk, Jeffrey \& Katz, (2013), might provide alternative self-soothing strategies to comfort 
spending. Group CBT with a focus on self-esteem has previously been used to tackle compulsive buying (Mitchell et al., 2006; Mueller et al., 2008), and the current results suggests that this might also be helpful for Bipolar Disorder specifically. Interventions to increased feeling of independence and find alternative ways to show affection rather than excessive generosity might help. Cognitive Behaviour Therapy may help tackle beliefs around achievement may reduce compulsive spending. Finally, relapse prevention work may help notice early warning signs of compulsive spending, for example plans to make money and develop practical coping strategies such as giving credit cards to a friend when unwell. However further research is needed to confirm the model in order to better identify mechanisms which might be targeted in interventions.

\section{Limitations and Future Research}

The strengths of this study include the longitudinal design and use of a number of different standardised measures of psychological and financial variables: most research in the area of financial and health is cross-sectional (Richardson et al., 2013).

A brief measure of gambling was used in this study but only two individuals reported yes to either of the two screening questions so the data could not be used here. Limitations include that the sample size was small, from one city and with a largely white sample. A major limitation of the sample size is that more sophisticated statistics such as mediation and multiple regression cannot be used, as such due to the number of statistics computed here there is an increased risk of a type I error. Future research should use a larger sample size and examine relationships over a longer period of time: the current follow-up time was only four months and stronger relationships might have been found over a longer period of time More recent measures have been developed for spending disorders (see Müller, Mitchell, Vogel, and de Zwaan,2017 for a review), however the measures used here was used due to a small 
number of questions for participants, and the alpha was excellent in the current sample.

There was a low opt-in rate to the study. It is possible that a confound in this study is that as participants were not paid to take part those who were struggling most financially might have been less likely to take part. It could also be that some potential participants were too mentally unwell to take part. The measures used here are for self-reported compulsive spending and thus it is not possible to say whether urges to spend actually translated into actual spending. Finally there are a number of other psychological factors which might be relevant but were not measured here for example Dittmar (2005) found that materialistic values were related to compulsive spending.

\section{Conclusions}

This study provides preliminary evidence that psychological factors are related to financial difficulties in Bipolar Disorder. The strongest effects are for compulsive spending which is fuelled by dysfunctional attitudes, poor mindful awareness and low self-esteem. Low self-esteem also appears to be exacerbated by financial worries in Bipolar disorder. Psychological variables such as self-esteem which have shown to be important factors in Bipolar Disorder also appear to be related to the financial difficulties. Future research should confirm these links and the proposed model in order to develop interventions specifically tailored to this problem in this population.

\section{Acknowledgements}

Thank you to the staff that referred and those who took part in the study. Thank you to Katherine Newman-Taylor for her advice on the model. This research was funded by Research Capability Funding from National Institute of Mental Health. 


\section{References}

American Psychiatric Association. (2013). Diagnostic and statistical manual of mental disorders (DSM-5®). American Psychiatric Pub.

Auerbach, R. P., \& Gardiner, C. K. (2012). Moving beyond the trait conceptualization of selfesteem: The prospective effect of impulsiveness, coping, and risky behavior engagement. Behaviour research and therapy, 50(10), 596-603.

Burdette, A. M., Hill, T. D., \& Hale, L. (2011). Household disrepair and the mental health of low-income urban women. Journal of Urban Health, 88(1), 142-153.

Brown, K. W., \& Ryan, R. M. (2003). The benefits of being present: mindfulness and its role in psychological well-being. Journal of personality and social psychology, 84(4), 822.

Chadwick, P., Kaur, H., Swelam, M., Ross, S., Ellett, L. (2011). Experience of mindfulness in people with Bipolar Disorder: a qualitative study. Psychotherapy Research 21, $277-285$.

Cheema, M. K., MacQueen, G. M., \& Hassel, S. (2015). Assessing personal financial management in patients with Bipolar Disorder and its relation to impulsivity and response inhibition. Cognitive neuropsychiatry, 20(5), 424-437.

Dittmar, H. (2005). Compulsive buying-a growing concern? An examination of gender, age, and endorsement of materialistic values as predictors. British Journal of Psychology, 96(4), 467-491.

Drentea, P., \& Reynolds, J. R. (2012). Neither a borrower nor a lender be: The relative importance of debt and SES for mental health among older adults. Journal of Aging and Health, 24(4), 673-695. Fletcher, K., Parker, G., Paterson, A., \& Synnott, H. (2013). High-risk behaviour in hypomanic states. Journal of affective disorders, $150(1), 50-56$. 
Johnson, S. L., Carver, C. S., \& Gotlib, I. H. (2012). Elevated ambitions for fame among persons diagnosed with bipolar I disorder. Journal of abnormal psychology, 121(3), 602.

Johnson, S. L., \& Carver, C. S. (2006). Extreme goal setting and vulnerability to mania among undiagnosed young adults. Cognitive Therapy and Research, 30(3), 377-395.

Johnson, S. L., Meyer, B., Winett, C., \& Small, J. (2000). Social support and self-esteem predict changes in bipolar depression but not mania. Journal of affective disorders, 58(1), 79-86.

Kesebir, S., İşitmez, S., \& Gündoğar, D. (2012). Compulsive buying in bipolar disorder: Is it a comorbidity or a complication? Journal of Affecitve Disorders, 1363), 797-802.

Lam, D., Wright, K., \& Smith, N. (2004). Dysfunctional assumptions in Bipolar Disorder. Journal of affective disorders, 79(1), 193-199.

Mansell, W., Morrison, A. P., Reid, G., Lowens, I., \& Tai, S. (2007). The interpretation of, and responses to, changes in internal states: An integrative cognitive model of mood swings and Bipolar Disorders. Behavioural and Cognitive Psychotherapy, 35(05), $515-539$.

Meeker, C. R., Geynisman, D. M., Egleston, B. L., Hall, M. J., Mechanic, K. Y., Bilusic, M., ... Lewis, B. (2016). Relationships among financial distress, emotional distress, and overall distress in insured patients with cancer. Journal of oncology practice, 12(7), e755-e764. Merikangas, K. R., Jin, R., He, J. P., Kessler, R. C., Lee, S., Sampson, N. A., ... \& Ladea, M. (2011). Prevalence and correlates of bipolar spectrum disorder in the world mental health survey initiative. Archives of general psychiatry, 68(3), 241251.

Miklowitz DJ, Alatiq Y, Goodwin GM et al. (2009). A pilot study of mindfulness-based cognitive therapy for Bipolar Disorder. Int J Cogn Therapy, 2:373-382.) 
Mitchell, J. E., Burgard, M., Faber, R., Crosby, R. D., \& de Zwaan, M. (2006). Cognitive behavioral therapy for compulsive buying disorder. Behaviour research and therapy, 44(12), 1859-1865.

Müller, A., Mitchell, J. E., Vogel, B., \& de Zwaan, M. (2017). New Assessment Tools for Buying Disorder. Current Addiction Reports, 4(3), 221-227.

Müller, A., Mitchell, J. E., \& de Zwaan, M. (2015). Compulsive buying. The American journal on addictions, 24(2), 132-137.

Mueller, A., Mueller, U., Silbermann, A., Reinecker, H., Bleich, S., Mitchell, J. E., \& de Zwaan, M. (2008). A randomized, controlled trial of group cognitive-behavioral therapy for compulsive buying disorder: posttreatment and 6-month follow-up results. The Journal of clinical psychiatry, 69(7), 1131-1138.

Murray, G., Leitan, N. D., Berk, M., Thomas, N., Michalak, E., Berk, L., . . . Allen, N. (2015). Online mindfulness-based intervention for late-stage bipolar disorder: pilot evidence for feasibility and effectiveness. Journal of affective disorders, 178, 46-51.

uhtadie, L., Johnson, S. L., Carver, C. S., Gotlib, I. H., \& Ketter, T. A. (2014). A profile approach to impulsivity in Bipolar Disorder: the key role of strong emotions. Acta Psychiatrica Scandinavica, 129(2), 100-108.

Najt, P., Perez, J., Sanches, M., Peluso, M. A. M., Glahn, D., \& Soares, J. C. (2007). Impulsivity and Bipolar Disorder. European Neuropsychopharmacology, 17(5), 313 320.

Nilsson, K. K., Jørgensen, C. R., Craig, T. K., Straarup, K. N., \& Licht, R. W. (2010). Selfesteem in remitted Bipolar Disorder patients: a meta-analysis. Bipolar Disorders, 12(6), 585-592.

Power, M. J., Katz, R., McGuffin, P., Duggan, C. F., Lam, D., \& Beck, A. T. (1994). The Dysfunctional Attitude Scale (DAS): A Comparison of Forms A and B and Proposals 
for a New Subscaled Version. Journal of Research in Personality, 28(3), 263-276. doi:http://dx.doi.org/10.1006/jrpe.1994.1019

Prawitz, A. D., Garman, E. T., Sorhaindo, B., O'Neill, B., Kim, J., \& Drentea, P. (2006). InCharge financial distress/financial well-being scale: Development, administration, and score interpretation. Journal of Financial Counseling and Planning, 17(1).

Richardson, T., Yeebo, M., Jansen, M., Elliott, P., \& Roberts, R. (2018). Financial difficulties and psychosis risk in British undergraduate students: a longitudinal analysis. Journal of Public Mental Health.

Richardson, T., Elliott, P., Roberts, R., \& Jansen, M. (2017). A longitudinal study of financial difficulties and mental health in a national sample of British undergraduate students. Community mental health journal, 53(3), 344-352.

Richardson, T., Elliott, P., \& Waller, G. (2015). Longitudinal relationships between financial stress and eating disorder features in undergraduate students. International Journal of Eating Disorders.

Richardson, T., Jansen M. \& Fitch, C. The Longitudinal Relationship between Financial Difficulties and Mental Health in Bipolar Disorder: A Preliminary Investigation. Submitted and under review by the Journal of Mental Health.

Richardson, T., Jansen, M., Turton, W. \& Bell, L. (2017). The Relationship Between Bipolar Disorder and Financial Difficulties: A Qualitative Examination of Patient's Views. Clinical Psychology Forum, 295, 2-6.

Richardson, T., Elliott, P., \& Roberts, R. (2013). The relationship between personal unsecured debt and mental and physical health: a systematic review and metaanalysis. Clinical psychology review, 33(8), 1148-1162. 
Rosenberg, M. (1989). Society and the adolescent self-image (rev: Wesleyan University Press.

Scott, J., Stanton, B., Garland, A., \& Ferrier, I. N. (2000). Cognitive vulnerability in patients with Bipolar Disorder. Psychological Medicine, 30(02), 467-472.

Siahpush, M., \& Carlin, J. B. (2006). Financial stress, smoking cessation and relapse: results from a prospective study of an Australian national sample. Addiction, 101(1), 121127.

Spinella, M. (2007). Normative data and a short form of the Barratt Impulsiveness Scale. International Journal of Neuroscience, 117(3), 359-368.

Strakowski, S. M., Fleck, D. E., DelBello, M. P., Adler, C. M., Shear, P. K., McElroy, S. L., ... \& Arndt, S. (2009). Characterizing impulsivity in mania. Bipolar Disorders, 11(1), 41-51.

Swann, A. C., Dougherty, D. M., Pazzaglia, P. J., Pham, M., Steinberg, J. L., \& Moeller, F. G. (2005). Increased impulsivity associated with severity of suicide attempt history in patients with bipolar disorder. American Journal of Psychiatry, 162(9), 1680-1687.

Swann, A. C., Anderson, J. C., Dougherty, D. M., \& Moeller, F. G. (2001). Measurement of inter-episode impulsivity in Bipolar Disorder. Psychiatry research, 101(2), 195-197.

Valence, G., d'Astous, A., \& Fortier, L. (1988). Compulsive buying: Concept and measurement. Journal of Consumer Policy, 11(4), 419-433.

Van Dijk, S., Jeffrey, J., \& Katz, M. R. (2013). A randomized, controlled, pilot study of dialectical behavior therapy skills in a psychoeducational group for individuals with Bipolar Disorder. Journal of affective disorders, 145(3), 386-393.

Weber, B., Jermann, F., Gex-Fabry, M., Nallet, A., Bondolfi, G., \& Aubry, J. M. (2010). Mindfulness-based cognitive therapy for Bipolar Disorder: a feasibility trial. European Psychiatry, 25(6), 334-337. 
Wickrama, K., Surjadi, F. F., Lorenz, F. O., Conger, R. D., \& O’Neal, C. W. (2012). Family economic hardship and progression of poor mental health in middle-aged husbands and wives. Family relations, 61(2), 297-312. Williams, J. M. G., Alatiq, Y., Crane, C., Barnhofer, T., Fennell, M. J., Duggan, D. S., ... \& Goodwin, G. M. (2008). Mindfulness-based cognitive therapy $(\mathrm{MBCT})$ in Bipolar Disorder: Preliminary evaluation of immediate effects on between-episode functioning. Journal of affective disorders, 107(1), 275-279.

Williams, A. D., \& Grisham, J. R. (2012). Impulsivity, emotion regulation, and mindful attentional focus in compulsive buying. Cognitive Therapy and Research, 36(5), 451457. 
Table 1:

Parametric and Parametric Correlations between Mental Health and Financial Variables at Baseline (one-tailed)

\begin{tabular}{|c|c|c|c|c|c|c|}
\hline 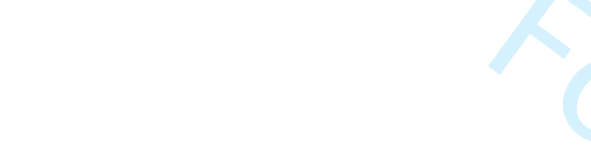 & $\begin{array}{c}\text { Self- } \\
\text { Esteem }\end{array}$ & $\begin{array}{c}\text { Mindful } \\
\text { Awareness }\end{array}$ & $\begin{array}{c}\text { Goal } \\
\text { Attainment }\end{array}$ & $\begin{array}{c}\text { Dependenc } \\
\mathbf{y}\end{array}$ & $\begin{array}{c}\text { Achievemen } \\
\mathbf{t}\end{array}$ & $\begin{array}{c}\text { Impulsivit } \\
\mathbf{y}\end{array}$ \\
\hline $\begin{array}{c}\text { Compulsive Buying Measurement } \\
\text { Scale }\end{array}$ & $r=-.41 * * *$ & $p=-.58 * * *$ & $r=.37 * *$ & $r=.36^{* *}$ & $r=.31 *$ & $r=.69 * * *$ \\
\hline Index of Financial Stress & $r h o=-.22$ & $r h o=-.40 * *$ & $r h o=-17$ & $r h o=.19$ & $r h o=-.13$ & $r h o=.41 * *$ \\
\hline Financial Distress/Wellbeing Scale & $r=-.43 * *$ & $r=.49 * * *$ & $r=-.15$ & $r=-.55 * * *$ & $r=-.39 * *$ & $r=-.58 * * *$ \\
\hline
\end{tabular}

$* * p<.01$ 
$* * p<.001$ 
Table 2:

Parametric and Parametric Correlations between Mental Health and Financial Variables at Baseline (one-tailed)

\begin{tabular}{|c|c|c|c|c|c|c|}
\hline Time 2 scores & & Baseline Scores & & & & \\
\hline & $\begin{array}{l}\text { Self-Esteem } \\
\text { (Rosenberg } \\
\text { Self-Esteem } \\
\text { Scale) } \\
\text { Baseline }(r)\end{array}$ & $\begin{array}{c}\text { Mindfulness } \\
\text { (Mindful Attention } \\
\text { Awareness Scale) } \\
\text { Baseline }(r)\end{array}$ & $\begin{array}{l}\text { Dysfunction } \\
\text { al Attitudes } \\
\text { Scale: Goal } \\
\text { Attainment } \\
\text { Baseline }(r)\end{array}$ & $\begin{array}{c}\text { Dysfunction } \\
\text { al Attitudes } \\
\text { Scale: } \\
\text { Dependency } \\
\text { Baseline }(r)\end{array}$ & $\begin{array}{l}\text { Dysfunction } \\
\text { al Attitudes } \\
\text { Scale: } \\
\text { Achievemen } \\
\text { t } \\
\text { Baseline }(r)\end{array}$ & $\begin{array}{r}\text { Impulsivity } \\
\text { (Barratt } \\
\text { Impulsivity } \\
\text { Scale) } \\
\text { Baseline ( } r \text { ) }\end{array}$ \\
\hline $\begin{array}{l}\text { Compulsive Buying (Compulsive } \\
\text { Buying Measurement Scale) } \\
\text { Time } 2 \\
\text { Time } 2 \text { (controlling baseline score) }\end{array}$ & $\begin{array}{l}-.54 * * * \\
-.39 * *\end{array}$ & $\begin{array}{l}-.68 * * * \\
-.46 * *\end{array}$ & $\begin{array}{l}.35 * \\
.10\end{array}$ & $\begin{array}{l}.45^{* *} \\
.42^{* *}\end{array}$ & $\begin{array}{l}.47 * * \\
.48 * *\end{array}$ & $\begin{array}{c}.58 * * * \\
.1\end{array}$ \\
\hline $\begin{array}{l}\text { Financial Distress/WellBeing } \\
\text { Scale } \\
\qquad \begin{array}{l}\text { Time } 2 \\
\end{array}\end{array}$ & $.29 *$ & .18 & NS at & .12 & -.17 & $-.34 *$ \\
\hline
\end{tabular}




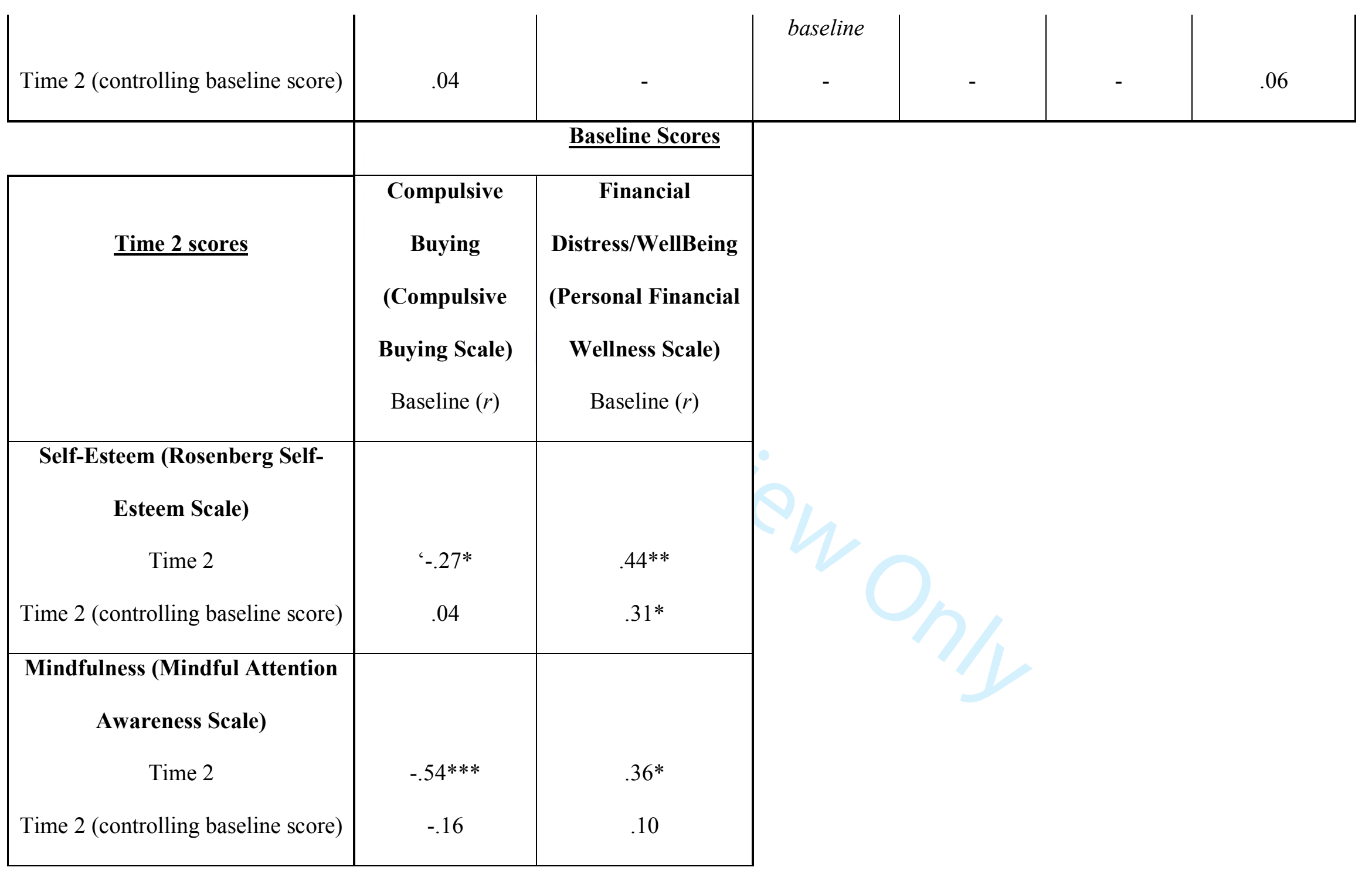




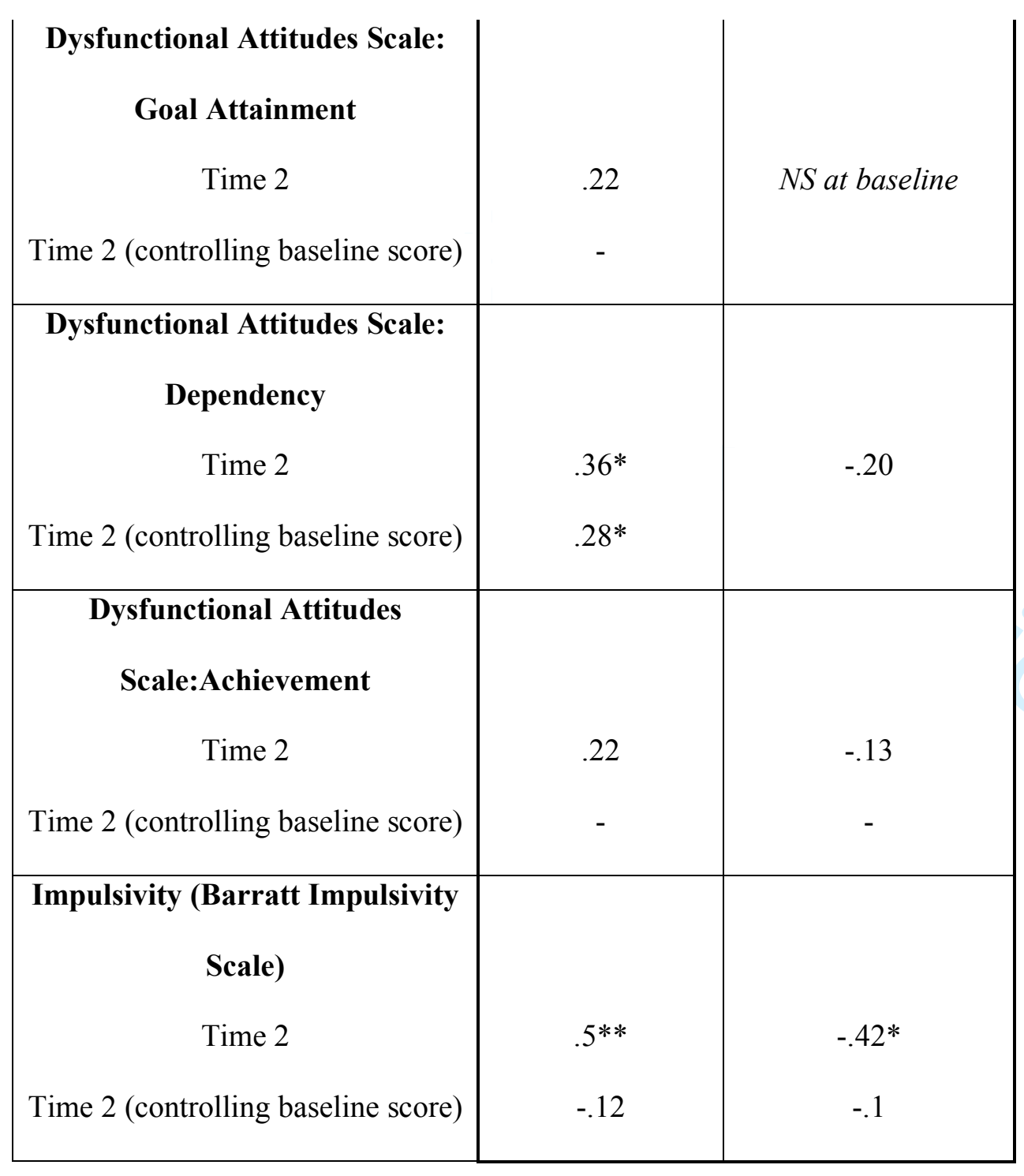




$$
\begin{aligned}
& * p<.05 \\
& * * p<.01 \\
& * * p<.001
\end{aligned}
$$


Table 3:

Summary of other findings from current sample to be incorporated into Model

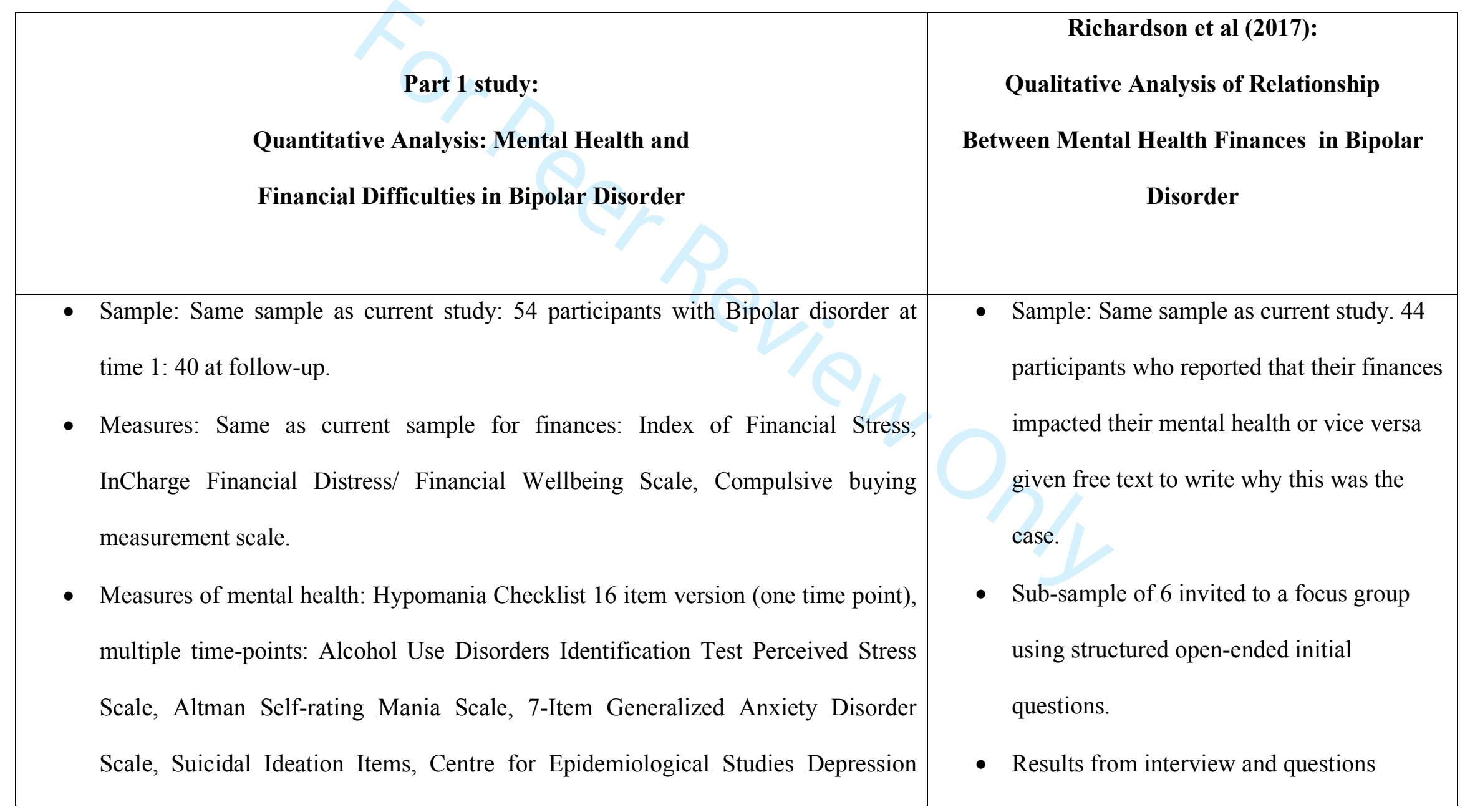




\section{Cross-sectional findings:}

- Going without items such as clothes due to financial difficulties linked to more symptoms depression, anxiety, stress and past hypomanic symptoms.

- Those currently on benefits had more symptoms of depression.

- Greater past hypomanic symptoms correlated with higher current scores on compulsive buying, lower current perceived financial wellness and greater current financial difficulties.

- No correlation between suicidality and financial variables.

- No impact on mental health of being unemployed, having a mortgage, income level, using less utilities, having a current loan or current credit card.

\section{Longitudinal findings (partial correlations with initial scores controlled for):}

- Poorer perceived financial wellness increased anxiety and stress over time, after controlling for baseline symptoms. No impact of any mental health measure on later perceived financial wellness.

Following themes emerged (number out of 44 whose answers fitted into this theme):

- Overspending including impulsive shopping ( $n=44)$ and excessive generosity $(n=6)$.

- Anxiety/Depression, $(n=29)$, including Suicidality $(n=7)$.

- $\quad$ Regret/Guilt $(n=10)$.

- Poor planning/Avoidant Coping, $(n=27)$.

- Vicious Cycle $(n=8)$.

- $\quad$ Comfort spending $(n=6)$.

- Impact on Employment,$(n=24)$. 
- More symptoms of stress, depression and anxiety increased scores buying scores after accounting for baseline compulsive spending. No impact of current manic symptoms.

- Compulsive shopping also increased anxiety over time suggesting a vicious cycle.

- Poorer perceived financial wellness increased anxiety and stress over time after controlling for initial symptoms. No impact on depression or manic symptoms. 
Figure 1:

Proposed Psychological Model of Relationships between Financial Difficulties and Mental Health in Bipolar Disorder

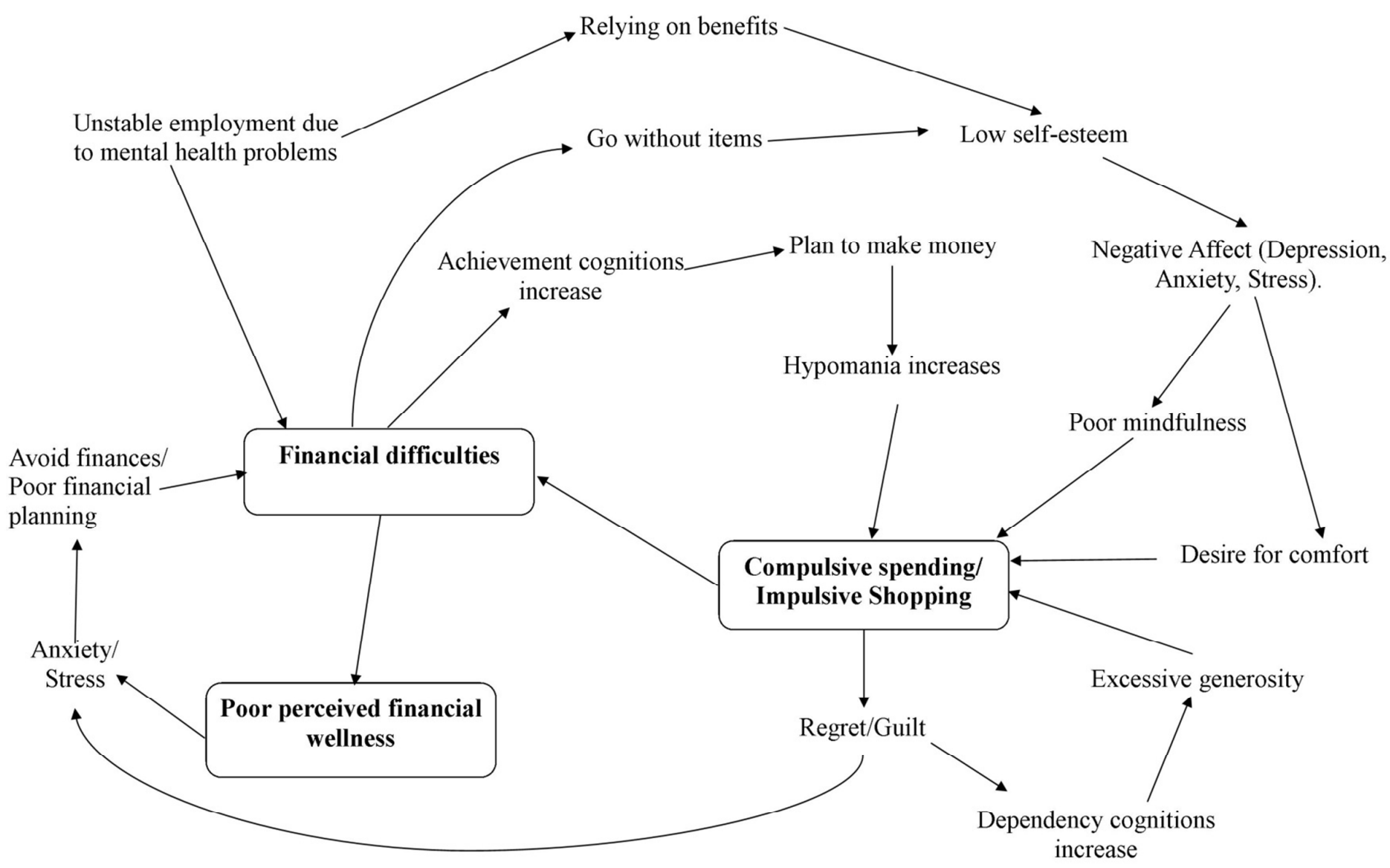

E-mail:jmh@iop.kcl.ac.uk URL: http://mc.manuscriptcentral.com/cjmh 